\title{
Research and construction of online knowledge resources Based on Internet and Multimedia Platform
}

\author{
Hong Zheng \\ QiLu University of Technology Jinan 250353, China. \\ zhh@qlu.edu.cn, 267353557@qq.com
}

Keywords: multimedia, construction of Internet platform, resources

\begin{abstract}
This essay discusses the significance of the construction of Internet and multimedia platform during IT times, brings about the problems in the construction, and proposes thoughts and suggestions, in order to provide reference for the practice of this field, realize the standardization of management information of multimedia classrooms, and promote the efficiency and level of management.
\end{abstract}

\section{Introduction}

As modern IT has spread into people's daily life, life-long education and personalized education have become basic features of social education today. This essay discusses the construction of digitalized learning platform and new mode of network education, in order to construct digitalized, virtual and intelligent classrooms based on national condition, and adopt good teaching resources in and out of the school via multimedia technology, share digitalized teaching resources, build searching engine, and assist teaching management, etc.. With mass storage of information, resources distributed in all fields can be organized, therefore, standardized education resources can be developed, as a result, the advantages of top schools can be brought out, a database of net resources can be constructed, teaching resources can be shared, which are a valid base for education reform and improving teaching quality.

Online education is the product of IT and modern teaching technology. Compared with traditional education, it can lead students to make efficient use of online resources. The construction of network needs the team cooperating together, and can encourage everyone in the management to involve in deciding.

\section{Construction of Multimedia Teaching Resource Pool}

\section{Function of Multimedia Teaching Resource Pool}

Planning and construction of courses are core of basic tasks of teaching, and their quality indicates the quality of school, which is the basic for fostering talents. Under the requirements of the development of science and technology, modern teaching equipment should be adopted to realize the best teaching results. It can be easily realized to inquire, search, edit, save and process the data in the multimedia teaching resource pool. The resources that can be watched and heard on teaching materials can boost the initiative of the students.

\section{Classification of Multimedia Teaching Resource Pool}

\section{Audio and Video Resources}

Audio and video resources developed by words and pictures can be gathered and be interacted with users, and courseware can be transferred in web pages via stream media technology. With stream media technology, files can be downloaded without waiting, and users can watch for study, which can be more intuitional and interesting. Therefore, the disadvantages of words - great length and dullness - can be avoided. The contents of courseware can be more diverse, which plenty of means can be added. 


\section{Net Resources}

Schools should give play to its own resources to support the resource data pool and the make of courseware, communicate more with other colleges and universities on resources, and construct net resources according to certain teaching targets and strategies. Net courses are interactive, shared, open, cooperative and initiative. The construction of online teaching resources is an important precondition of online education, and the feature of online education is to acquire abundant teaching resources in a convenient way.

In order to conduct online education, teachers should keep pace with the development of technology, change traditional teaching perception, and avoid copying traditional teaching mode into online teaching.

\section{Problems of construction of online learning resources}

\section{Lacking of practices}

Online education is carried out only by face-to-face instant supervision by teachers and has not become really practical teaching, and this makes it insufficient to supervise and evaluate students' learning results. In spite of abundant resources, there are problems of lack of face-to-face teaching, various teaching quality and techniques, etc..

\section{Resources are not well-organized}

The resources for online education are not well organized, and are usually separate among different subjects, plus the high costs and lack of sharing, online education has not been spread widely. For the sake of lack of techniques, computers cannot evaluate students' learning results, and there is insufficient communication among teachers and students, besides, computers can in no way take the place of real teachers, therefore, online education needs to be improved.

\section{The structure of digitalized resources is loose}

Assisting teaching platform should supply the function of questionnaire for convenience for teachers to do researches on students. And the utilization with the purpose increase students' interests in learning would raise the cost of equipment.

\section{Management of Multimedia Net Platform}

\section{Attach Importance to the Construction and Management of Net Platform}

Hardware of net platform is the base of all teaching resources. As the development of multimedia teaching resources, the resources need continuous enrichment and completion. Therefore, there should be no delay to improve inner construction and management. The daily maintain of equipment, such as projection, curtain, computers, loudspeakers and wires, provides basic functions in the system. Since departments tend to construct platforms respectively and have deficient communication and planning, the advantages of resources in some universities can not be fully brought into play, which will lower the service quality of online education.

What's more, it is trivial work to manage teaching resources. For the purpose of a steady and secure system, several hardware platforms of international standards should be adopted, including Unix, NetWare, Windows NT, etc.. The task of management of education resources should be a multimedia teaching network which can assist teaching and researching activities efficiently. Besides, teachers can choose the tool of knowledge management according to their own condition and adjust themselves to the requirements of multimedia education.

\section{Construction of Campus Network}

The construction of campus network has become a significant part of infrastructure of universities, and the nuclear part of spiritual civilization and culture of universities. Therefore, we should spare no efforts to construct campus network. We should combine the real needs of our school to its future development. On the other hand, we should make integrated analysis and demonstration to determine the scheme of network construction and management. What's 
important is that the purpose of standardization is to avoid unnecessary reconstruction of teaching resources and to realize max sharing of resources.

At present, there are several types of backbone structure.

(1)FDDI (Fiber Distributed Data Interface): This is a LAN technology developed since 1980s. It is of high redundancy and fault tolerance. But the equipment is of higher prices and the connecting technology is comparatively complicated.

(2)ATM (Asynchronous Transfer Mode): This is a new technology developed for supporting B-ISDN. It can transfer data at high speed, including audio and video signals, data, faxes and images, and is suitable for LAN and WAN.

(3)Gigabit Ethernet: It is constructed on ether standard. It is of high efficiency, high speed, high capability, compatibility and interoperability, and is quite practical.

\section{Research on Teaching Mode of Net Multimedia}

Online teaching refers to applying net technology into teaching activities, through which learners can study on their initiative, and teachers can maintain a class atmosphere, so that a interactive teaching information processing system can be formed.

\section{Enlarge the coverage of resources and sharing}

It is more important for learners to gain more and advanced front technology and information, and the construction of computer network would help to achieve this. The usage of resource pools is not confined to uploading and downloading the resources one needs. Individual users should make more sharing and be a part of the group of learning.

The biggest advantage of online teaching is interaction and sharing. Teachers instruct the students who are the major body of education, create real circumstances, provide various resources for them, organize students to cooperate to carry on study activities, and encourage them to find out the interconnection among things. Students can choose proper learning strategies through net platform and adjust study notions and methods in order to carry out autonomous learning.

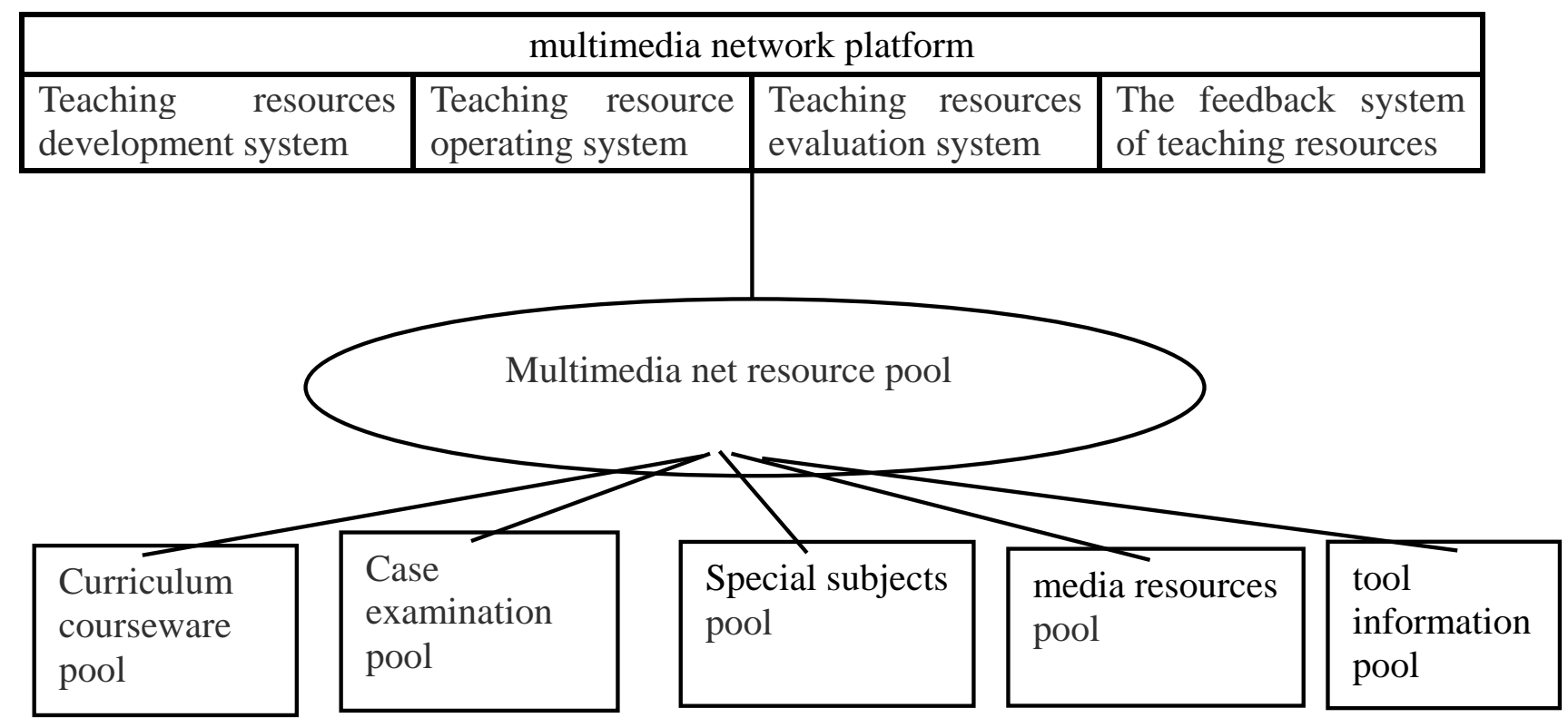

Figure 1 Structure of multimedia net platform

Sharing and interaction of study resources have decisive meaning for online education. Although present net technology has provided the fundamental technical conditions for using and sharing education resources, it has to be net platform and construction of teaching resources that can realize the sharing of resources. Resource construction is the core task for the construction specialized teaching resource pool. The lowest elements in Figure 1 are spread in mass storage. Resource construction includes making standards for resources, and organize resources according to different needs and platforms. 


\section{Improve intelligent management via IT}

Intelligent management should be improved to improve to organizing multimedia classrooms and IOT technology, ensure the development of new technology and teaching resource pools, and share the excellent courses without the limit of time and location. Students can conduct study activities according to his own condition, and communicate on the platform for a remedy to classrooms. Therefore, knowledge and information of course resources can be networking, digitalized and intelligent.

\section{Conclusion}

Based on multimedia online teaching platform, students' initiative can be improved, research level can be promoted, and repetitive work can be reduced. The platform can also be a place for students to show their study results, and for teachers to study and summarize to improve themselves. The media of online resources is a mode of courseware resource pool, explores the interactive idea of resource construction, and is advanced for improving the use and sharing of online teaching resources.It maximizes the resources, ensures the biggest function of network for students.

\section{References}

[1] Yanyan Zhao, Higher Education Services Targeted at Information Technology Inquiry[J], Computer Knowledge and Technology, (2013)5500-5502.

[2] Lingling Hao, Build Network Platform Enhance the Level of Multimedia Teaching[J], Science and Technology Information, (2009)524-528.

[3] Min Cai, Zhaoxia Zhang, Yanlan Liang, Kunpeng Zhang, The research of learning strategies of local colleges and Universities under the environment of multimedia teaching [J], Journal of Anyang Normal College, (2010)117-119.

[4] Yaonan Liu, A Study on the Application of Network Teaching in Continuing Education in Local Colleges and Universities[J], Adult Education, 304(2012)28-30.

[5] Guodong Fang, Xiaojing Li,Cong Wang, The Managerial Potentiality of Network Teaching Resources and The Design of Network Learning Process Management[J], Modern Educational Technology, (2012)76-78.

[6] Huan Chen, Network Video Monitoring in the Application of the Multimedia Classroom Management[J], Computer\&Communication, (2013)103-104.

[7] Xianghong Zeng, The Discussion about the construction of network teaching platform[J], Computer Knowledge Technology, (2013)5257-5258.

[8] Jing Li, Junzheng Wang, Wei Shen, A Study on Remote Supervisory System Based on B/S and Streaming Media Technology[J], Transactions of Beijing Institute of Technology,(2008)682-686.

[9] Ronghuai Huang, Web-based Cooperative Learning System Model[J], Remote Education of China, 523(2011)222-223.

[10] Haiping Huang, Ruchuan Wang, Xiaolong Xu, The Research of Internet Multimedia-Teaching System Model Based Multi-Agent Cooperation[M].Journal of Nanjing University of Posts and Telecommunications,(2004)74-79.

[11] Shengkui Huang, Shu Pu, Yan Zhang, Remote Teaching Platform Research Based on Self-study Ability Training of Students[J],Journal of Chengdu Textile College, (2011)51-53. 